\title{
The Assessment of the
} \section{Innovativeness of a New Medicine in Italy}

\section{OPEN ACCESS}

Edited by:

Sandor Kerpel-Fronius,

Semmelweis University, Hungary

Reviewed by:

Georgi Iskrov,

Plovdiv Medical University, Bulgaria Katsura Tsukamoto,

Gifu Pharmaceutical University, Japan

${ }^{*}$ Correspondence:

Filomena Fortinguerra

f.fortinguerra@aifa.gov.it

tThese authors have contributed equally to this work and share first authorship

¥Scientific \& Technical Committee (Commissione Tecnico-Scientifica, CTS) of Italian Medicines Agency-AIFA: Patrizia Popoli, Antonio

Addis, Armando Genazzani, Anna Maria Marata, Mauro Biffoni, Carlo Caltagirone, Giovambattista De Sarro, Ida Fortino, Paolo Schinchariol, Nicola Magrini

Specialty section

This article was submitted to Regulatory Science,

a section of the journa

Frontiers in Medicine

Received: 12 October 2021 Accepted: 08 November 2021 Published: 08 December 2021

Citation: Fortinguerra F, Perna S, Marini R, Dell'Utri A, Trapanese M, Trotta F and Scientific \& Technical Committee

(Commissione Tecnico-Scientifica,

CTS) of

Italian Medicines Agency-AIFA (2021) The Assessment of the Innovativeness of a New Medicine in Italy. Front. Med. 8:793640. doi: 10.3389/fmed.2021.793640

\author{
Filomena Fortinguerra ${ }^{*}$, Serena Perna ${ }^{\dagger}$, Roberto Marini, Alessandra Dell'Utri, \\ Maurizio Trapanese, Francesco Trotta and \\ Scientific \& Technical Committee (Commissione Tecnico-Scientifica, CTS) of \\ Italian Medicines Agency-AIFA ${ }^{\ddagger}$
}

Italian Medicines Agency, Rome, Italy

Objectives: Starting from April 2017, the Italian Medicine Agency (AIFA) has approved new criteria for defining any new medicinal product with an innovative indication. The purpose of the study is to analyze the activity of innovativeness evaluation according to the new approach, to estimate the weight of each criterion considered for innovativeness definition, and to evaluate how the new approach works in terms of consistency and reproducibility.

Methods: A retrospective analysis was performed on the final reports evaluating the drug innovativeness assessment published on the AlFA's website between April 2017 and January 2021. Descriptive statistics, chi-square test, whether the conditions were respected, or Fisher's exact test was used to explore the association between characteristics of drugs and the innovativeness status and the association between the three criteria. Profiles of the decision process and their relationship with innovativeness response were described. In order to evaluate the weight of each criterion in predicting the innovativeness status, a Classification Tree (CT) algorithm was applied.

Results: Overall, of the 109 published drugs reports, 37 (33.9\%) were recognized as fully innovative, 29 (26.6\%) were considered conditionally innovative, while for 43 (39.4\%) reports innovativeness was not recognized. Considering the three criteria of the decision process, the added therapeutic value was the only criterion statistically associated with a drug's degree of innovation $(p<0.001)$. The therapeutic need and the quality of clinical evidence were statistically associated $(p=0.008)$ even if only a mild association was observed. The added therapeutic value was the most important variable in predicting the innovativeness status according to the classification tree (CT) model applied, achieving an accuracy of $89.4 \%$. No difference was found between orphans and non-orphan drugs or oncological and non-oncological drugs.

Discussion: The added therapeutic value is the most important criterion of the multidimensional approach for the innovativeness status definition of a new medical product. A mild association was found between the therapeutic need and the quality of evidence. Overall, similar decision profiles bring the same evaluation of innovativeness status, indicating a good consistency and reproducibility between decisions.

Keywords: innovativeness, drug therapy, therapeutic need, added therapeutic value, grade 


\section{INTRODUCTION}

Currently, the assessment of the innovativeness of a new medicine and the transparent disclosure of the information on the decision-making process are a challenge for many regulatory agencies and health organizations worldwide $(1,2)$.

In April 2017, new criteria to define the innovativeness of a medicine were approved by the Italian Medicine Agency (AIFA). According to the new approach, as described in our previous paper (3), the decision process used to define the innovativeness of a drug takes into account three criteria, the therapeutic need, the added therapeutic value, and the quality of clinical evidence, which is assessed based on the GRADE (Grading of Recommendations Assessment, Development, and Evaluation) methodology (Box 1).
The final judgment expressed in relation to an individual therapeutic indication of a medicine is formulated on a combination profile deriving from the set of evaluation levels for each criterion. The overall assessment process resulted in a new medicinal product being awarded one of the following three innovative statuses by a specific therapeutic indication: "fully innovative," "conditionally innovative," or "non-innovative." The assessment process was performed by the Scientific and Technical Committee (Commissione Tecnico-Scientifica, CTS) of AIFA, which adopted the final decision when deciding on reimbursement and price of a new medicine (or new therapeutic indication); for each assessment, a full report explaining the rationale for the final decision is made publicly available on the Agency's website (4).

BOX 1 | The AIFA criteria for assessing a drug's degree of innovation.

\begin{tabular}{|c|c|c|c|c|c|}
\hline \multirow{2}{*}{$\begin{array}{l}\text { Criterion } \\
\text { Therapeutic } \\
\text { need }\end{array}$} & \multicolumn{5}{|c|}{ Level } \\
\hline & $\begin{array}{l}\text { Maximum (no alternative } \\
\text { therapeutic options available) }\end{array}$ & $\begin{array}{l}\text { Important (alternative } \\
\text { therapeutic options available, } \\
\text { with no impact on clinically } \\
\text { relevant outcomes) }\end{array}$ & $\begin{array}{l}\text { Moderate (alternative } \\
\text { therapeutic options available } \\
\text { with limited impact on } \\
\text { clinically relevant outcomes, } \\
\text { and/or uncertain or not } \\
\text { satisfactory safety profile) }\end{array}$ & $\begin{array}{l}\text { Poor (alternative therapeutic } \\
\text { options available with high } \\
\text { impact on clinically relevant } \\
\text { outcomes and a satisfactory } \\
\text { safety profile) }\end{array}$ & $\begin{array}{l}\text { Absent (alternative } \\
\text { therapeutic options available, } \\
\text { which are able to slow down } \\
\text { the progression of the } \\
\text { disease and have a } \\
\text { satisfactory safety profile) }\end{array}$ \\
\hline $\begin{array}{l}\text { Added } \\
\text { therapeutic } \\
\text { value }\end{array}$ & $\begin{array}{l}\text { Maximum (greater efficacy } \\
\text { than alternative therapeutic } \\
\text { options (if available) in } \\
\text { clinically relevant outcomes, } \\
\text { ideally curing the disease or } \\
\text { altering its natural history) }\end{array}$ & $\begin{array}{l}\text { Important (greater efficacy } \\
\text { based on clinically relevant } \\
\text { outcomes, or alternatively } \\
\text { one of the following options: } \\
\text { i) the drug can reduce the } \\
\text { risk of seriously debilitating or } \\
\text { life-threatening } \\
\text { complications, } \\
\text { ii) the drug has a better } \\
\text { risk/benefit ratio compared } \\
\text { to the alternative therapeutic } \\
\text { options, } \\
\text { iii) the drug can avoid the use } \\
\text { of high risk clinical } \\
\text { procedures, } \\
\text { iv) the drug can significantly } \\
\text { change the natural history of } \\
\text { the disease in a } \\
\text { subpopulation of patients, } \\
\text { v) the drug can provide a } \\
\text { clinically relevant added value } \\
\text { e.g., in terms of quality of life } \\
\text { and disease-free interval, } \\
\text { compared to the available } \\
\text { therapeutic options) }\end{array}$ & $\begin{array}{l}\text { Moderate (a slightly better } \\
\text { efficacy profile or improved } \\
\text { efficacy in some patient } \\
\text { subpopulations or based on } \\
\text { surrogate endpoints and has } \\
\text { limited impact on the quality } \\
\text { of life. For situations when } \\
\text { the lack of a study } \\
\text { comparator is acceptable, } \\
\text { evidence showing relative } \\
\text { efficacy compared to the } \\
\text { available therapeutic options } \\
\text { should be taken into } \\
\text { account) }\end{array}$ & $\begin{array}{l}\text { Poor (greater efficacy only for } \\
\text { non-clinically relevant } \\
\text { outcomes or based on a } \\
\text { poor magnitude of effect. } \\
\text { The drug offers minor } \\
\text { benefits (e.g., favorable } \\
\text { routes of administration) } \\
\text { compared to the available } \\
\text { therapeutic options) }\end{array}$ & $\begin{array}{l}\text { Absent (no added } \\
\text { therapeutic benefit } \\
\text { compared to the alternative } \\
\text { available therapeutic options) }\end{array}$ \\
\hline $\begin{array}{l}\text { Quality of } \\
\text { clinical } \\
\text { evidence* }\end{array}$ & High & & Moderate & Low & Very low \\
\hline $\begin{array}{l}\text { Innovativeness } \\
\text { status }\end{array}$ & Fully (innovative) & & $\begin{array}{l}\text { Conditional (conditionally } \\
\text { innovative) }\end{array}$ & & Absent (non-innovative) \\
\hline $\begin{array}{l}\text { Commercial } \\
\text { implication }\end{array}$ & $\begin{array}{l}\text { - Funded via "innovative drug } \\
\text { - No payback mechanism } \\
\text { - Immediate inclusion into regi } \\
\text { - Benefit duration period up to }\end{array}$ & $\begin{array}{l}\text { fund" } \\
\text { gional drug formularies } \\
36 \text { months }\end{array}$ & $\begin{array}{l}\text { Immediate inclusion into } \\
\text { regional drug formularies }\end{array}$ & & No benefits \\
\hline
\end{tabular}

${ }^{*}$ An orphan drug can still be considered innovative, even if the quality of clinical evidence is low or very low when the other two criteria are evaluated as maximum or important. Adapted from (3). 
The AIFA's model, which is structured and flexible at the same time, ensures that the panel members of CTS consider all the important factors for making a decision, helping them to make discussions about the best available evidence about each criterion and to identify reasons for disagreements. The systematic, rigorous, and transparent assessment process, incorporating explicit decision-making criteria, as in the AIFA's model, aims to address the most common limitations of the decisionmaking process in healthcare, such as lack of consistency and transparency (5). Furthermore, the choice of AIFA to wield the GRADE methodology to evaluate the quality of clinical evidence within a process of drug innovativeness assessments could support the early identification of the discrepancy between the available clinical evidence at the time of market approval and the need of patients for rapid access to such innovative therapies.

The aim of the present study is to analyze the assessment reports by AIFA's CTS according to the new approach in order to estimate the weight of each criterion considered for the definition of drug innovativeness, the potential interdependence between the three criteria, the consistency between the final decisions emerging from the decision-making process, and their capacity in predicting the final decision in order to understand how the framework works.

\section{METHODS}

\section{Data and Variables of Interest}

The final reports evaluating the innovativeness assessment by a specific therapeutic indication of a medicine published on the AIFA's website between April 2017 and January 2021 were collected and analyzed. From each report, the following data were extracted and tabulated: the drug name, the therapeutic indication, the type of medicine (e.g., oncological or orphan drug), the rank assigned to each criterion (therapeutic need, added therapeutic value, quality of clinical evidence), and the final decision on drug innovativeness ("fully innovative," "conditionally Innovative," or "non-innovative").

\section{Statistical Analysis}

Categorical data were summarized as numbers $(n)$ and frequencies (\%). Profiles of the decision process and its relationship with the decision on drug innovativeness were described in order to investigate the impact of the three domains on the final decision.

A comparison between orphan and non-orphan drugs and oncological and non-oncological drugs was also performed in order to evaluate if the orphan status or an oncological indication have an impact on the weight of criteria in predicting the drug innovativeness.

The association between categorical variables was assessed by Chi-square test, when the conditions were respected, or Fisher's exact test. Moreover, Cramér's V was calculated to assess the strength of the association between the three criteria utilized to define the innovativeness status of a drug. In order to evaluate the weight of each criterion in predicting the innovativeness status, a Classification Tree (CT) algorithm was applied. A CT is a non-parametric model using a tree structure to explore the relationship of a set of potential exploratory variables by developing decision rules for the prediction of a categorical response variable, such as the innovative status. A classification tree consists of three types of nodes: (1)root node, the top node of the tree comprising all the data; (2) splitting node, a node that assigns data to a subgroup; and (3) terminal node, final decision (outcome) $(6,7)$.

The tree-fitting process initially proceeds by finding the covariate that "best" divides the statistical units into two groups. The "best" split is defined as the one that results in the most homogeneous subgroups with respect to the response variable, according to specific standard measures of goodness-of-fit. The process then separates the observations into the two resulting groups and repeats the splitting process in each of the two groups, a process referred to as recursive partitioning (8). In particular, in the present analysis, the CT was performed using the recursive partitioning classification model which identifies the optimal tree using one procedure divided into two phases: a first phase sees the growth of the trees-according to the maximum decrease in impurity (in our case the Gini index); later the tree in question is pruned through cross-validation method, i.e., minimizing the cross-validated misclassification error across competing sub-trees (the complexity parameter (CP) used to prune the tree was fixed at 0.01) (9-13). The confusion matrix and correct classification rate were calculated to assess the model prediction performance. All analyses were performed using $\mathrm{R}$ version 3.5.2 (14). In particular, "rpart" package was used to implement the CT algorithm (15). A two-sided $p$-value less than 0.05 was considered statistically significant.

\section{RESULTS}

Overall, of the 109 published drugs reports, 37 (33.9\%) were recognized as fully innovative, $29(26.6 \%)$ were considered conditionally innovative while for 43 (39.4\%) reports innovativeness was not recognized (Table 1). Overall, 67 (61.5\%) reports concerned oncological indications (24 innovative, 20 conditionally innovative, 23 non-innovative), 41 (37.6\%) reports concerned orphan indications (16 innovative, 11 conditionally innovative, 14 non-innovative); and 24 (22.0\%) reports were on both oncological and orphan indications (10 innovative, 6 conditionally innovative, 8 non-innovative). While the majority of oncological or orphan drugs were recognized as fully or conditionally innovative, the majority of non-oncological and non-orphan indications were evaluated as non-innovative $(32.6 \%)$.

Considering the three criteria of the decision process, the therapeutic need was not statistically associated with innovativeness status; however, fully innovative reports presented an important therapeutic need (45.9\%) more frequently than the other two groups, conditionally innovative (24.1\%) and non-innovative (27.9\%). Instead, conditionally innovative assessments reported a "moderate" therapeutic need (62.1\%) more frequently than non-innovative (51.2\%) and fully innovative $(40.5 \%)$ reports. Moreover, a "poor" therapeutic value was observed only for non-innovative reports (11.6\%). 
TABLE 1 | Characteristics of drugs criteria considering the drug's degree of innovation.

\begin{tabular}{|c|c|c|c|c|c|c|c|}
\hline & \multirow{2}{*}{\multicolumn{2}{|c|}{$\begin{array}{l}\text { Fully innovative } \\
\qquad n=37\end{array}$}} & \multirow{2}{*}{\multicolumn{2}{|c|}{$\begin{array}{c}\text { Conditionally innovative } \\
\qquad n=29\end{array}$}} & \multirow{2}{*}{\multicolumn{2}{|c|}{$\begin{array}{c}\text { Non-innovative }^{\dagger} \\
n=43\end{array}$}} & \multirow{3}{*}{$\begin{array}{c}\boldsymbol{p} \text {-value }{ }^{*} \\
0.363\end{array}$} \\
\hline & & & & & & & \\
\hline Oncological drug & 24 & 64.9 & 20 & 69.0 & 23 & 53.5 & \\
\hline Orphan drug & 16 & 43.2 & 11 & 37.9 & 14 & 32.6 & 0.616 \\
\hline Oncological and orphan drug & 10 & 27.0 & 6 & 20.7 & 8 & 18.6 & 0.645 \\
\hline Non-oncological and non-orphan drug & 7 & 18.9 & 4 & 13.8 & 14 & 32.6 & 0.155 \\
\hline \multicolumn{8}{|l|}{ Therapeutic need } \\
\hline Maximum & 5 & 13.5 & 4 & 13.8 & 4 & 9.3 & \multirow[t]{5}{*}{0.081} \\
\hline Important & 17 & 45.9 & 7 & 24.1 & 12 & 27.9 & \\
\hline Moderate & 15 & 40.5 & 18 & 62.1 & 22 & 51.2 & \\
\hline Poor & 0 & 0.0 & 0 & 0.0 & 5 & 11.6 & \\
\hline Absent & 0 & 0.0 & 0 & 0.0 & 0 & 0.0 & \\
\hline \multicolumn{8}{|l|}{ Added therapeutic value } \\
\hline Maximum & 1 & 2.7 & 0 & 0.0 & 0 & 0.0 & \multirow[t]{5}{*}{$<0.001$} \\
\hline Important & 31 & 83.8 & 0 & 0.0 & 1 & 2.6 & \\
\hline Moderate & 5 & 13.5 & 29 & 100.0 & 5 & 13.2 & \\
\hline Poor & 0 & 0.0 & 0 & 0.0 & 29 & 76.3 & \\
\hline Absent & 0 & 0.0 & 0 & 0.0 & 3 & 7.9 & \\
\hline \multicolumn{8}{|l|}{ Quality of clinical evidence } \\
\hline High & 10 & 27.0 & 3 & 10.3 & 5 & 11.6 & \multirow[t]{4}{*}{0.451} \\
\hline Moderate & 19 & 51.4 & 18 & 62.1 & 24 & 55.8 & \\
\hline Low & 7 & 18.9 & 6 & 20.7 & 9 & 20.9 & \\
\hline Very low & 1 & 2.7 & 2 & 6.9 & 5 & 11.6 & \\
\hline
\end{tabular}

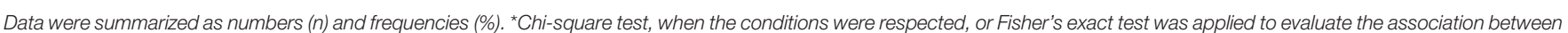
categorical variables. ${ }^{\dagger}$ For five observations the added therapeutic value was "Untestable" and therefore classified as NA.

The added therapeutic value was the only criteria statistically associated with the drug innovation degree $(p<0.001)$. In particular, among the final reports analyzed, an "important" added therapeutic value was more frequently observed (83.8\%) in the indications where full innovativeness was recognized; the added therapeutic value was defined as "moderate" for the totality $(100 \%)$ of conditionally innovative indications, while a higher percentage of "poor" (76.3\%) level of added therapeutic value was observed in the groups of indications defined as non-innovative.

In addition, no difference was found comparing orphan and non-orphan drugs in the weight of each criterion in the assessment process (Supplementary Table 1) and oncological and non-oncological drugs (Supplementary Table 4). For both the drug groups the added therapeutic value remained the only criteria statistically associated with the drug innovation degree $(p<0.001)$.

The quality of clinical evidence was defined as "moderate" in most cases, independently from the drug innovation degree. However, fully innovative indications presented more frequently "high" quality level (27.0\%) in comparison to conditionally innovative $(10.3 \%)$ and non-innovative $(11.6 \%)$ ones, and by contrast, non-innovative drugs presented more frequently "very low" quality level of clinical evidence $(11.6 \%)$ in comparison to fully and conditionally innovative drugs (2.7 and 6.9\%, respectively). As shown in Table 2, the therapeutic need and the quality of clinical evidence were statistically associated $(p=0.008)$, even if only a mild association was observed (Cramér's V: 0.25). Comparing orphans to non-orphan drugs and oncological to non-oncological medicines the association between the therapeutic need and the quality of clinical evidence was not significant (Supplementary Tables 2, 5).

The analysis of all possible combinations of the three criteria used to define drug innovativeness showed 37 different evaluation profiles; the most frequent combination $(13.8 \%)$ was represented by the "moderate" level reached for all three criteria, followed by the combination Moderate/Poor/Moderate and Moderate/Important/Moderate with the same percentage (9.0\%) (Table 3). Furthermore, in most cases, the same profile observed was linked to the same final decision. For example, the 15 therapeutic indications rated as "Moderate/Moderate/Moderate" were classified always as conditionally innovative while the other two most frequent profiles "Moderate/Poor/Moderate" and "Moderate/Important/Moderate" were classified always as non-innovative and fully innovative, respectively. From these combinations, it was possible to observe also the role played by the quality of clinical evidence criterion. In fact, considering the two different patterns "Important/Moderate/High" $(n=5$; $4.6 \%)$ and "Important/Moderate/Low" ( $n=4 ; 3.7 \%)$ which differ only for the quality level of clinical evidence, the majority of reports were classified as fully innovative (80\%) in the first case, whereas in the second case they were classified either as conditionally innovative $(50 \%)$ or as non-innovative $(50 \%)$. Furthermore, the observed criteria combination patterns were 
TABLE 2 | Relationship between criteria utilized in the multidimensional approach in defining innovativeness of a new medicine.

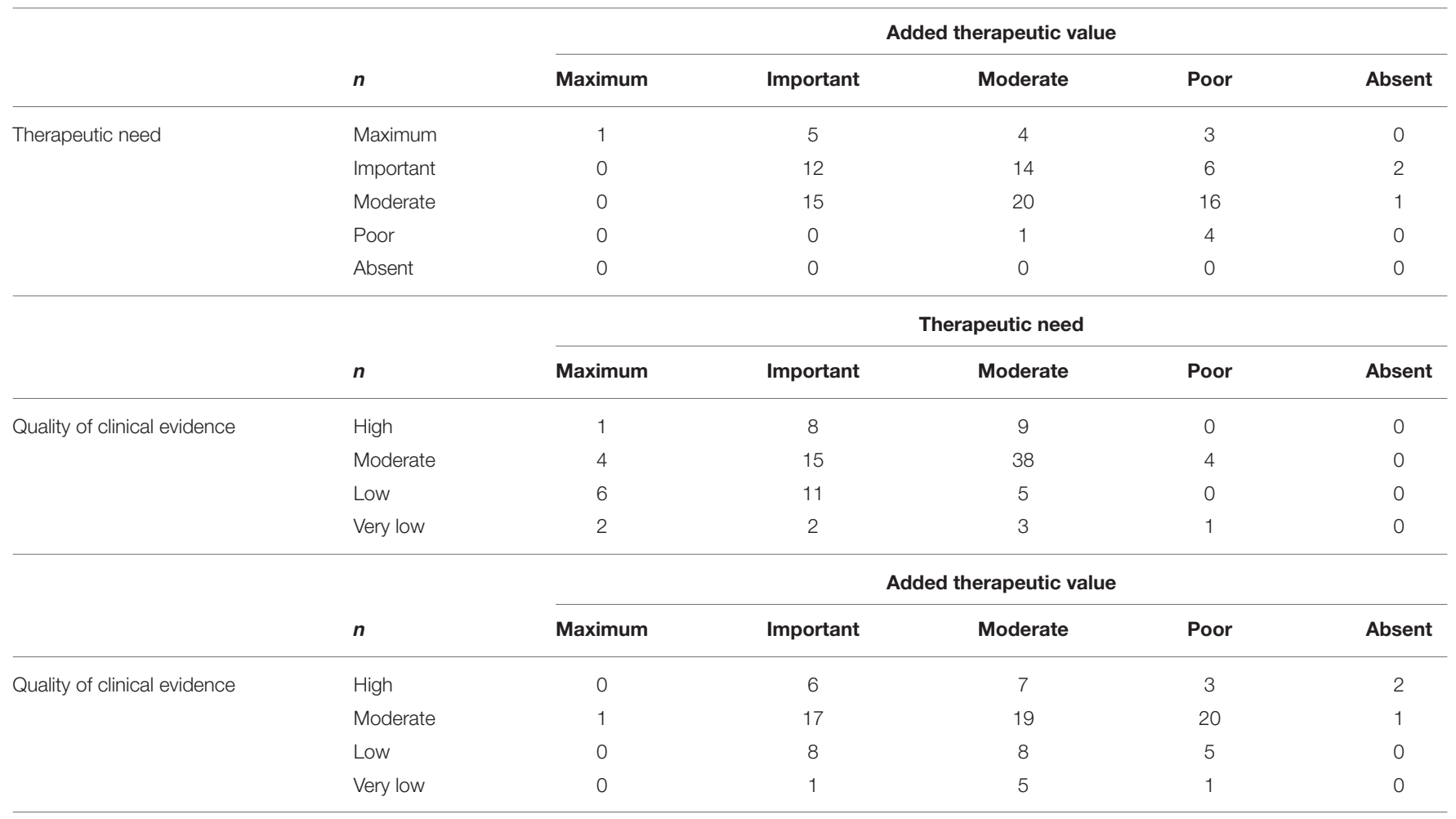

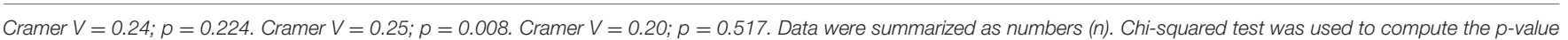
for Cramer's $V$.

not so much altered when separating orphans from nonorphan drugs (Supplementary Table 3) and oncological from non-oncological drugs (Supplementary Table 6).

The CT model confirmed the previous results. As shown by Figure 1, the added therapeutic value was the most important variable in predicting the innovativeness status. In the first split, the "poor" or "absent" level of the added therapeutic value distinguished a final node of 32 reports whose predicted class was no innovativeness. In the second split, the remaining 72 reports were divided into two final nodes according to the following rule: "maximum" or "important" added therapeutic values distinguished a final node of 33 reports whose predicted class was fully innovative, otherwise the predicted class was conditional innovativeness. The CT achieved an accuracy of $89.4 \%$ for the entire sample. Unaltered results were observed repeating the CT model and splitting the entire sample in training and test samples (results not shown).

\section{DISCUSSION}

To date, this study represents the most updated analysis of the AIFA's assessment reports of drug innovativeness, since the new approach using GRADE methodology was adopted by AIFA in order to evaluate the innovativeness of medications in Italy.

First of all, our study showed that the type of medicine, oncological or orphan drug, does not influence the final decision on drug innovativeness, suggesting that these characteristics cannot be considered as determinants of drug innovativeness.

We know that drugs may be considered "Fully Innovative" if both the therapeutic need and the added therapeutic value were recognized as "Maximum" or "Important" and the quality of the clinical evidence as "High." On the other hand, a drug cannot be recognized innovative if the therapeutic need and/or the added therapeutic value was judged as "poor" or "absent," or if the quality of clinical evidence was judged to be "low" or "very low" (with the exception of the orphan drugs, which can achieve the "Fully Innovative" status even with low or very low quality of clinical evidence).

Intermediate situations are evaluated case by case, taking into account the relative weight of each criterion. We found that the added therapeutic value was the only criteria statistically associated with drug innovation degree, suggesting that it is the most important criterion for the definition of the innovative status of a new medicine or a new therapeutic indication. This means that the rate of the clinical benefits is the determinant of the innovativeness status and that the extent of clinical efficacy of a medicine, measured on clinically relevant endpoints, when compared to the available alternative treatments, is the crucial factor in recognizing a medicine as fully innovative. This association was confirmed also when separating orphan drugs from non-orphans and oncological drugs from nononcological ones.

Moreover, we found that if the added therapeutic value is moderate, then the quality of clinical evidence has a determinant 
TABLE 3 | Criteria combination patterns in relation to drug innovativeness definition.

\begin{tabular}{|c|c|c|c|c|c|c|}
\hline $\begin{array}{l}\text { Therapeutic } \\
\text { need }\end{array}$ & $\begin{array}{l}\text { Added therapeutic } \\
\text { value }\end{array}$ & $\begin{array}{l}\text { Quality of clinical } \\
\text { evidence }\end{array}$ & $n$ & $\begin{array}{c}\text { Fully } \\
\text { innovative (\%) }\end{array}$ & $\begin{array}{c}\text { Conditionally } \\
\text { innovative (\%) }\end{array}$ & $\begin{array}{c}\text { Non-innovative } \\
\text { (\%) }\end{array}$ \\
\hline Moderate & Moderate & Moderate & 15 & 0 & 100 & 0 \\
\hline Moderate & Important & Moderate & 10 & 100 & 0 & 0 \\
\hline Important & Important & Moderate & 6 & 100 & 0 & 0 \\
\hline Moderate & Important & High & 4 & 100 & 0 & 0 \\
\hline Important & Poor & Moderate & 4 & 0 & 0 & 100 \\
\hline Important & Moderate & Low & 4 & 0 & 50 & 50 \\
\hline Important & Moderate & Moderate & 4 & 25 & 75 & 0 \\
\hline Important & Important & Low & 4 & 100 & 0 & 0 \\
\hline Moderate & Moderate & Very low & 2 & 0 & 0 & 100 \\
\hline Moderate & Moderate & Low & 2 & 0 & 100 & 0 \\
\hline Important & Poor & Low & 2 & 0 & 0 & 100 \\
\hline Important & Important & High & 2 & 100 & 0 & 0 \\
\hline Maximum & Poor & Moderate & 2 & 0 & 0 & 100 \\
\hline Maximum & Moderate & Low & 2 & 0 & 100 & 0 \\
\hline Poor & Moderate & Very low & 1 & 0 & 0 & 100 \\
\hline Moderate & Absent & High & 1 & 0 & 0 & 100 \\
\hline Moderate & Poor & Very low & 1 & 0 & 0 & 100 \\
\hline Moderate & Moderate & High & 1 & 0 & 100 & 0 \\
\hline Maximum & Moderate & Very low & 1 & 0 & 100 & 0 \\
\hline Maximum & Moderate & High & 1 & 0 & 100 & 0 \\
\hline Maximum & Important & Very low & 1 & 100 & 0 & 0 \\
\hline Maximum & Important & Moderate & 1 & 100 & 0 & 0 \\
\hline \multirow[t]{2}{*}{ Maximum } & Maximum & Moderate & 1 & 100 & 0 & 0 \\
\hline & & & 109 & & & \\
\hline
\end{tabular}

Combination patterns are ordered by decreasing frequency (n).

role in the decision. The therapeutic need, evaluated as the availability of alternative therapies, seems to have no determinant role in the final decision.

The analysis of all possible combinations of the three criteria used to define innovativeness of a drug showed a mild association between two criteria of the AIFA's approach, the therapeutic need, and the quality of clinical evidence. In most cases the same observed profile was linked to the same decision on drug innovativeness, thus we can assume that similar decision profiles bring to the same evaluation of innovativeness status, indicating a good consistency between decisions. This applies also to analyzing orphans/non-orphans and oncological/nononcological drugs separately.

Based on the publicly available assessment reports, a classification tree model was used to understand how the framework works as well as to identify the most important criteria in predicting the final decision. The CT model confirmed that the added therapeutic value was the most important determinant on innovativeness decision, followed by quality of evidence, mainly when the added therapeutic value was evaluated as moderate. In addition, the therapeutic need seems to have no relevant role in the evaluation. Unaltered results were observed 
A
- Fully Innovative
- Conditionally innovative
- Non Innovative
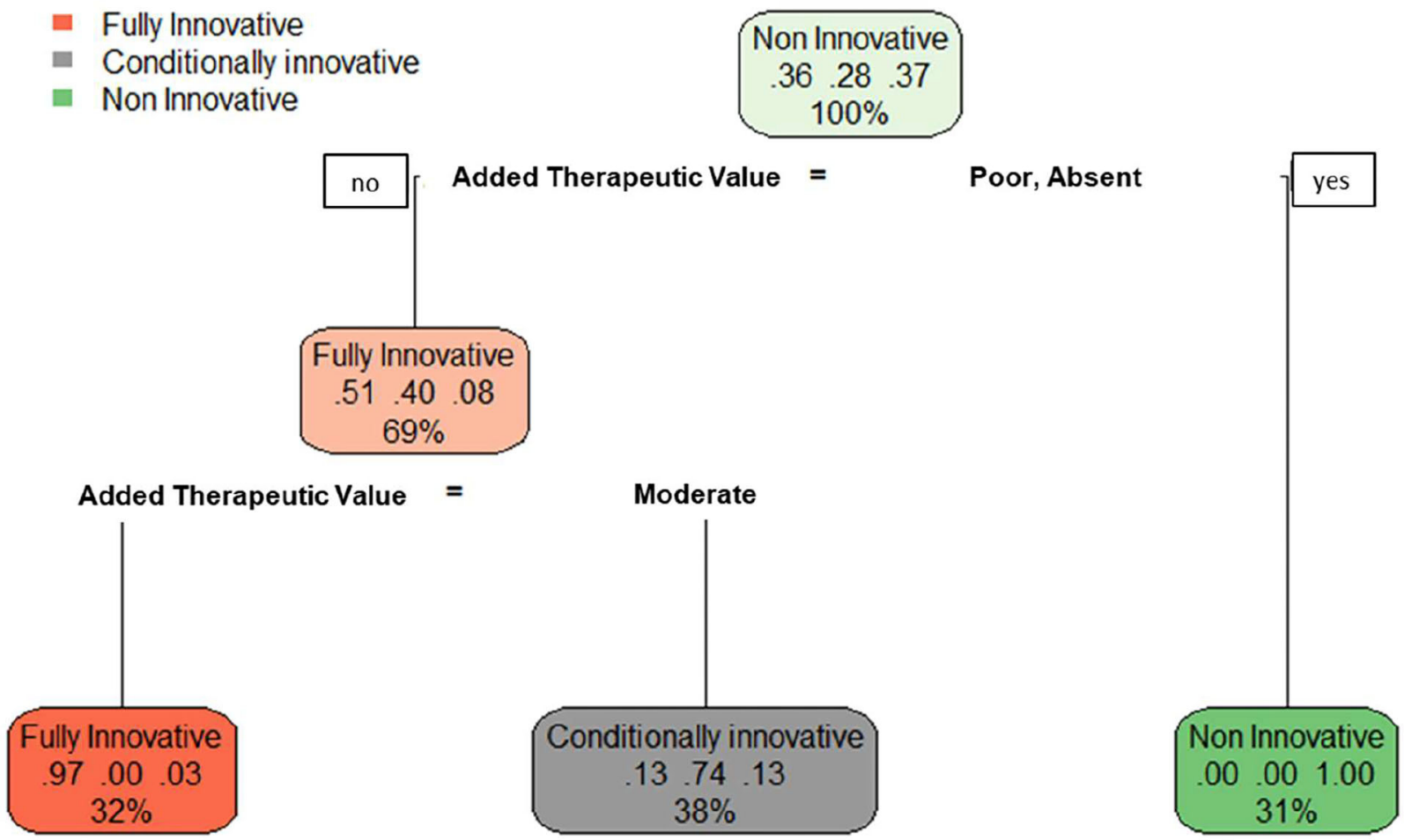

B

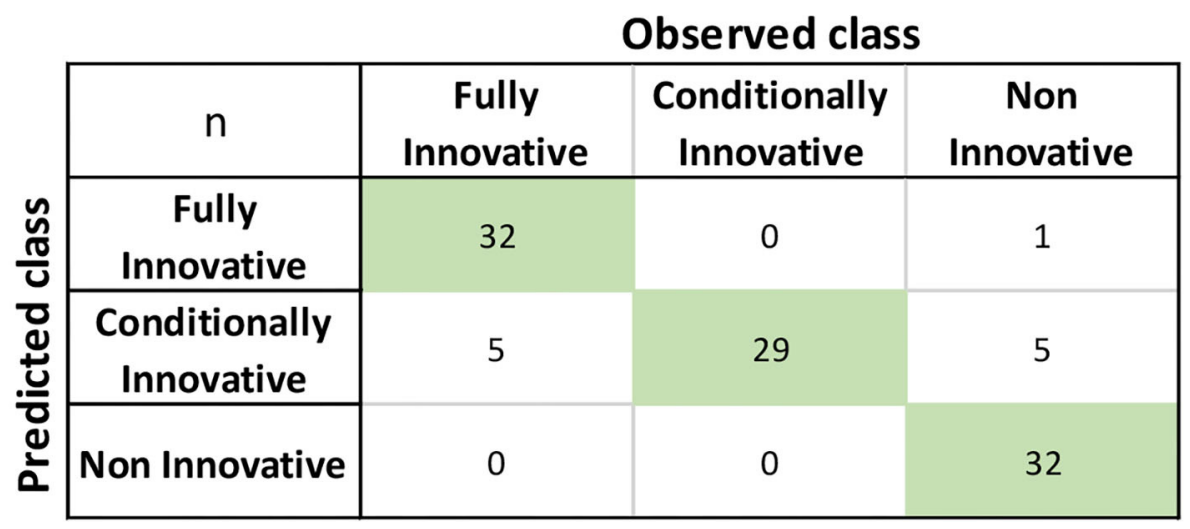

Correct Classification Rate $=89.4 \%$

FIGURE 1 | (A) Illustration of classification tree built according to recursive partitioning (RPART) ${ }^{3}$ model for the evaluation of drug's innovation and (B) confusion matrix of the predicted vs observed classification responses for the complete sample without missing values $(n=104)$. In each node are reported three main pieces of information: in the first line the name of the "most" frequent category of the outcome variable, in the second line the percentage for each category on the total amount of node observations, and in the third line the percentage of observations within the node on the total amount used in the model ( $n=104)$. For example, in the root node, the most frequent outcome's category is "Non-innovative," with a percentage of $37 \%$. The root node contains the total amount of observations (100\%) used in the model. While in the splitting node the most frequent outcome's category is "Fully innovative" for $51 \%$ of nodes observations which contains $69 \%$ of the total amount of observations. 
when repeating the CT model by splitting the entire sample in training and test samples, thus showing good performance of the model in predicting the final decision.

Our study confirms the results of a previously published paper (16), including a limited number of appraisals, and showing that the added therapeutic value has the greatest impact on the final decision of the appraisal of drug innovativeness. However, our analysis was more extensive than the previous one, because it was based on a larger number of appraisals and included the evaluation of the potential interdependence between criteria and the application of a classification tree model, which was found to efficiently predict the final decision.

As far as the decisions on drug innovativeness can be arbitrary, this study confirmed that the AIFA's multidimensional approach, which is well-structured and flexible at the same time, provides a systematic approach in the assessment in order to minimize biases and improve consistency of the decisions. The application of the three criteria in a decision framework, including the GRADE methodology in evaluating the quality of clinical evidence, goes in the direction of improving the transparency and reproducibility of the decision-making process on drug innovativeness.

Beyond a few methodological and procedural differences, the Italian model for drug innovativeness designation (3) could be considered quite similar to systems used in other European countries, in particular in the evaluation of the added therapeutic value. For example, in France and Italy, the added therapeutic value can range across 5 levels, whereas in Germany six categories were identified $(17,18)$. However, in Italy, the added therapeutic value of a medicine represents the leading criterion for the definition of drug innovativeness, whereas in France and Germany the evaluation of the added health-related benefits poses the basis for the negotiation of the reimbursed price/discounts $(19,20)$. In addition, some similarities exist between these rankings and the way to measure the added therapeutic value of a medicine in the NICE approach for appraising innovative technologies in the $\operatorname{UK}(21,22)$.

Furthermore, in Italy, the quality of evidence is assessed through the GRADE approach and ranked in four levels. In Germany, both the number and characteristics of clinical studies as well as the certainty of results and observed effects are ranked in four classes of evidence quality (23). In France, the quality of studies is taken into account, although without a defined classification system. In Italy and France, surrogate endpoints are accepted if no other endpoints are available; in Germany, these are considered only if validated. Finally, Italy and Germany apply specific rules (e.g., accepting a low level of quality of evidence) for orphan medicines $(24,25)$.

Even in the USA, the breakthrough therapy designation by Food and Drug Administration (FDA) was created in 2012 to expedite the development and review of drugs intended to treat a serious or life-threatening disease that, based on preliminary evidence, were expected to provide substantial benefits over existing therapies on a clinically significant endpoint(s) $(26,27)$.

Although with a different role played by the three criteria within the HTA process in the various countries, there is some evidence of a harmonized approach to recognize an innovative medicine, which should guarantee equity in the access to innovative medicines for European patients. Moreover, we would highlight that, within the context of the European countries, Italy is the only one where the "innovative status" is granted on a wellstructured and reproducible model, with a list of innovative (and non-innovative) medicines made publicly available.

Despite the fact that our study results should be consolidated through further analyses based on a larger sample of appraisals, our study showed the benefits of the model adopted in Italy for drug "innovative" designation for decision-makers (AIFA), who would have an efficient and transparent methodology to make decisions on drug innovativeness and for patients, who could have more rapid access to new innovative medicines.

In conclusion, this article provides an extensive overview of AIFA's published assessment reports on drug innovativeness in Italy, identifying the determinants of drug innovativeness and both the accuracy and consistency of the assessments across the last 3 years. We confirmed that the multidimensional approach chosen by AIFA since April 2017 reached the intended purpose of the Italian regulatory Agency both in terms of transparency and accountability of the decision-making process applied to innovative medicines.

\section{DATA AVAILABILITY STATEMENT}

The datasets presented in this study can be found in online repositories. The names of the repository/repositories and accession number(s) can be found below: https://www.aifa.gov. it/web/guest/farmaci-innovativi.

\section{AUTHOR CONTRIBUTIONS}

SP, FF, and FT: conception and study design. FF: collection and assembly of data. SP, RM, and FF: analysis and interpretation. FT, MT, and AD: methodological advice. FF and SP: manuscript writing. All authors read, revised, and approved the final manuscript.

\section{ACKNOWLEDGMENTS}

We are grateful to Dr. Linda Pierattini for language editing.

\section{SUPPLEMENTARY MATERIAL}

The Supplementary Material for this article can be found online at: https://www.frontiersin.org/articles/10.3389/fmed. 2021.793640/full\#supplementary-material 


\section{REFERENCES}

1. Tutone M, Villa F, Addis A, Trotta F, Tafuri G. How do drug regulatory bodies deal with potential innovative therapies? Ther Innov Regul Sci. (2020) 54:195-9. doi: 10.1007/s43441-019-00045-x

2. Kesselheim AS, Wang B, Avorn J. Defining "innovativeness" in drug development: a systematic review. Clin Pharmacol Ther. (2013) 94:336-48. doi: 10.1038/clpt.2013.115

3. Fortinguerra F, Tafuri G, Trotta F, Addis A. Using GRADE methodology to assess innovation of new medicinal products in Italy. $\mathrm{Br} J$ Clin Pharmacol. (2020) 86:93-105. doi: 10.1111/bcp.14138

4. Agenzia Italiana del Farmaco (AIFA). Report di Valutazione Dell'innovatività per Indicazione Terapeutica. Available online at: https://www.aifa.gov.it/web/ guest/farmaci-innovativi (accessed October 10, 2021).

5. Panteli D, Nolting A, Eckhardt H, Kulig M, Busse R. Published and unpublished evidence in coverage decision-making for pharmaceuticals in Europe: existing approaches and way forward. Health Res Policy Syst. (2016) 14:6. doi: 10.1186/s12961-016-0080-9

6. Huang JZ. An introduction to statistical learning: with applications in $\mathrm{R}$ By Gareth James, Trevor Hastie, Robert Tibshirani, Daniela Witten. JABES. (2014) 19:556-7. doi: 10.1007/s13253-014-0179-9

7. Song YY, Lu Y. Decision tree methods: applications for classification and prediction. Shanghai Arch Psychiatry. (2015) 27:130-5. doi: 10.11919/j.issn.1002-0829.215044

8. Martin MA, Meyricke R, O’Neill T, Roberts S. Mastectomy or breast conserving surgery? Factors affecting type of surgical treatment for breast cancer-a classification tree approach. BMC Cancer. (2006) 6:98. doi: 10.1186/1471-2407-6-98

9. Breiman L, Friedman JH, Olshen RA, Stone CJ. Classification and Regression Trees. 1st ed. Boca Raton, Routledge (1984).

10. Clark LA, Pregibon D. Tree-based models. In: Chambers JM, Hastie TJ, editors. Statistical Models in S. New York, NY: Chapman and Hall/CRC (1992). p. 377-420. doi: 10.1201/9780203738535-9

11. $\mathrm{Li} \mathrm{Y}$, Rapkin B. Classification and regression tree uncovered hierarchy of psychosocial determinants underlying quality of life response shift in HIV/AIDS. J Clin Epidemiol. (2009) 62:1138-47. doi: 10.1016/j.jclinepi.2009.03.021

12. Zhang H, Singer B. Recursive Partitioning in The Health Sciences. New York, NY: Springer-Verlag (1999). doi: 10.1007/978-1-4757-3027-2

13. Zhu MY, Zou X, Li Q, Yu DM, Yang ZT, Huang. D, et al. A novel noninvasive algorithm for the assessment of liver fibrosis in patients with chronic hepatitis B virus infection. J Viral Hepat. (2017) 24:589-98. doi: 10.1111/jvh.12682

14. R Core Team. R: A Language and Environment for Statistical Computing. Vienna: R Foundation for Statistical Computing (2018). Available online at: https://www.R-project.org (accessed October 10, 2021).

15. Therneau TM, Atkinson EJ. An Introduction to Recursive Partitioning Using The Rpart Routines. Rochester, MN: Mayo Foundation (2019). Available online at: https://cran.r-project.org/web/packages/rpart/vignettes/longintro. pdf (accessed October 10, 2021).

16. Galeone C, Bruzzi P, Jommi C. Key drivers of innovativeness appraisal for medicines: the Italian experience after the adoption of the new ranking system. BMJ Open. (2021) 11:e041259. doi: 10.1136/bmjopen-2020-041259

17. Ruof J, Schwartz FW, Schulenburg JM, Dintsios CM. Early benefit assessment (EBA) in Germany: analysing decisions 18 months after introducing the new AMNOG legislation. Eur J Health Econ. (2014) 15:577-89. doi: 10.1007/s10198-013-0495-y
18. Dubromel A, Geffroy L, Aulagner G, Dussart C. Assessment and diffusion of medical innovations in France: an overview. J Mark Access Health Policy. (2018) 6:1458575. doi: 10.1080/20016689.2018.14 58575

19. Kleijnen S, Lipska I, Leonardo Alves T, Meijboom K, Elsada A, Vervölgyi $\mathrm{V}$, et al. Relative effectiveness assessments of oncology medicines for pricing and reimbursement decisions in European countries. Ann Oncol. (2016) 27:1768-75. doi: 10.1093/annonc/mdw233

20. Theidel U, von der Schulenburg J-MG. Benefit assessment in Germany: implications for price discounts. Health Econ Rev. (2016) 6:1-12. doi: 10.1186/s13561-016-0109-3

21. Drummond M, de Pouvourville G, Jones E, Haig J, Saba G, Cawston H. A comparative analysis of two contrasting European approaches for rewarding the value added by drugs for cancer: England versus France. Pharmacoeconomics. (2014) 32:509-20. doi: 10.1007/s40273-014-0144-z

22. Charlton V, Rid A. Innovation as a value in healthcare prioritysetting: the UK experience. Soc Justice Res. (2019) 32:208-38. doi: 10.1007/s11211-019-00333-9

23. Institute for Quality and Efficiency in Health Care (IQWiG). General Methods. Version 4.1 of 28 November 2013. Available online at: https://www.iqwig.de/ download/IQWiG_General_Methods_Version_\%204-1.pdf

24. Van Wilder P, Mabilia V, Kuipers Cavaco Y, McGuinn J. Towards a Harmonised EU Assessment of the Added Therapeutic Value of Medicines. (2015). Available online at" http://www.europarl.europa.eu/RegData/etudes/ STUD/2015/542219/IPOL_STU2015542219_EN.pdf (accessed October 10, 2021).

25. Panteli D, Arickx F, Cleemput I, Dedet G, Eckhardt H, Fogarty E, et al. Pharmaceutical regulation in 15 European countries review. Health Syst Transit. (2016) 18:1-122.

26. Pregelj L, Hine DC, Kesselheim AS, Darrow JJ. Assessing the impact of US Food and Drug Administration breakthrough therapy designation timing on trial characteristics and development speed. Clin Pharmacol Ther. (2021) 110:1018-24. doi: 10.1002/cpt.2318

27. Puthumana J, Wallach JD, Ross JS. Clinical trial evidence supporting FDA approval of drugs granted breakthrough therapy designation. JAMA. (2018) 320:301-3. doi: 10.1001/jama.2018.7619

Conflict of Interest: The authors declare that the research was conducted in the absence of any commercial or financial relationships that could be construed as a potential conflict of interest.

Publisher's Note: All claims expressed in this article are solely those of the authors and do not necessarily represent those of their affiliated organizations, or those of the publisher, the editors and the reviewers. Any product that may be evaluated in this article, or claim that may be made by its manufacturer, is not guaranteed or endorsed by the publisher.

Copyright (C) 2021 Fortinguerra, Perna, Marini, Dell'Utri, Trapanese, Trotta and Scientific \& Technical Committee (Commissione Tecnico-Scientifica, CTS) of Italian Medicines Agency-AIFA. This is an open-access article distributed under the terms of the Creative Commons Attribution License (CC BY). The use, distribution or reproduction in other forums is permitted, provided the original author(s) and the copyright owner(s) are credited and that the original publication in this journal is cited, in accordance with accepted academic practice. No use, distribution or reproduction is permitted which does not comply with these terms. 